\title{
STRUCTURE REFINEMENT OF AMORPHOUS Cd-As BY ANALYSIS OF PARTIAL RADIAL DISTRIBUTION FUNCTIONS
}

\author{
A. Burian \\ Institute of Engineering Problems, University of Silesia \\ Śnieżna 2, 41-200 Sosnowiec, Poland \\ and \\ Department of Solid State Physics, Polish Academy of Sciences \\ Wandy 3, 41-800 Zabrze, Poland
}

The anomalous wide angle X-ray scattering technique was used to determine the partial structure factors and then the partial radial distribution functions for vacuum evaporated Cd-As amorphous films containing 41 and $74 \%$ at. As. The experiments were performed using synchrotron radiation tuned near the As and Cd absorption edges. The obtained structural information about the individual $\mathrm{Cd}-\mathrm{Cd}, \mathrm{Cd}-\mathrm{As}$ and As-As correlations shows that $\mathrm{As}$ and $\mathrm{Cd}$ remain almost tetrahedrally coordinated and suggest a certain degree of chemical disorder of the investigated samples.

PACS numbers: 61.43.-j, 61.43.Bn, 61.43.Dq

\section{Introduction}

In the structural study of non-crystalline materials there is much interest in maximizing the amount of information about such systems. For materials containing $n$ atomic species there are $n(n+1) / 2$ distinct correlations, which in a conventional scattering experiment are inseparable. The extended X-ray absorption fine structure (EXAFS) and differential anomalous wide angle X-ray scattering techniques probe the environment of a selected atomic species, but in the case of multicomponent materials the different partial contributions, involving this species, may be merged in the near- and next-neighbour coordination spheres being indistinguishable. The resonant changes in the X-ray atomic scattering factors can be used to vary the weights $W_{i j}(K)$ of the individual partial structure factors (PSFs) $S_{i j}(K)$ to the intensity scattered by a multicomponent material and then to determine PSFs $[1,2]$.

$$
S(K)=\sum_{i=1}^{n} \sum_{j=1}^{n} W_{i j}(K) S_{i j}(K)
$$


where

$$
W_{i j}(K)=c_{i} c_{j} \operatorname{Re}\left(\frac{f_{i}(K) f_{j}^{*}(K)}{\left\langle f_{i}(K)\right\rangle^{2}}\right),
$$

$\langle f\rangle^{2}=\left|\sum_{i=1}^{n} f_{i}\right|^{2}$, the scattering vector $K=4 \pi \sin \theta / \lambda, 2 \theta$ is the scattering angle, $\lambda$ is the wavelength and $c_{i}$ is the atomic concentration.

Although possibility of application of this method was recognized by Keating (1963) [1], the availability of intense radiation sources as synchrotrons has recently made it possible to perform the anomalous wide angle X-ray scattering (AWAXS) experiments. The measurements of the intensities scattered by a non-crystalline sample carried out using the incident beam energies tuned near the absorption edges of the components can be utilized to construct a system of simultaneous linear equations (1). However, the changes in the atomic scattering factors, achieved in the AWAXS experiment lead to the relatively weak variations in the $W_{i j}$ coefficients. This prevents from a reliable determination of the PSFs using the standard linear least squares method because the normal equations are very close to singular. In order to obtain the solution of the system (1) a combined biased estimator, which utilizes the regularization and truncated singular value decomposition methods, has been applied to minimize the effects of ill-conditioning of the problem $[3,4]$. The AWAXS data for the amorphous $\mathrm{Cd}_{59} \mathrm{As}_{41}$ and $\mathrm{Cd}_{26} \mathrm{As}_{74}$ films were collected on the wiggler beam line of the DCI storage ring at LURE (Orsay, France). The experiments and the numerical routines are described in detail in [3-6]. It should be pointed out that knowledge of the partial radial distribution functions (PRDFs) is the most complete information which can be obtained from a scattering experiment.

\section{Results and discussion}

The PRDFs are computed from the experimentally determined PSFs by the Fourier sine transform as follows:

$$
4 \pi r^{2} \rho_{i j}(r)=c_{j}\left[4 \pi r^{2} \rho_{0}+r G_{i j}(r)\right],
$$

where

$$
G_{i j}(r)=\frac{2}{\pi} \int_{0}^{K_{\max }} S\left[S_{i j}(K)-1\right] \exp \left(-0.02 K^{2}\right) \sin (K r) \mathrm{d} K
$$

and $\rho_{0}$ is the average atomic density. The experimental PRDFs are shown in Figs. 1 and 2 .

The structural parameters: the interatomic distances $\left(r_{i}\right)$, their standard deviations $\left(\sigma_{i}\right)$ and the coordination numbers $\left(N_{i}\right)$ can be obtained using the curve-fitting, method which utilizes the Hook-Jeeves type procedure [7], expressing PRDF as

$$
\begin{aligned}
& 4 \pi r^{2} \rho_{i j}(r)=r \sum_{i} \int_{0}^{\infty} \frac{N_{i}}{r_{i}}\left\{\exp \left[-\frac{\left(r^{\prime}-r_{i}\right)}{2 \sigma_{i}^{2}}\right]-\exp \left[-\frac{\left(r^{\prime}+r_{i}\right)}{2 \sigma_{i}^{2}}\right]\right\} \\
& \quad \times\left[P\left(r-r^{\prime}\right)-P\left(r+r^{\prime}\right)\right] \mathrm{d} r^{\prime}
\end{aligned}
$$


where

$$
P(r)=\frac{1}{\pi} \int_{0}^{K_{\max }} \exp \left(-0.02 K^{2}\right) \cos (K r) \mathrm{d} K
$$

and the sum is taken over all coordination spheres.

The experimental PRDFs obtained for the $\mathrm{Cd}_{59} \mathrm{As}_{41}$ and $\mathrm{Cd}_{26} \mathrm{As}_{74}$ amorphous films have been interpreted as described above, basing on Eq. (5). From inspection of the plots presented in Figs. 1 and 2 it can be seen that the near-neighbour coordination sphere for $\mathrm{Cd}_{59} \mathrm{As}_{41}$ is predominant by the $\mathrm{Cd}-\mathrm{As}$ correlations, whereas this $r$ region is mostly influenced by the As-As and Cd-As pairs for $\mathrm{Cd}_{26} \mathrm{As}_{74}$. This is consistent with an expectation that the occurrence of the contributions involving As is more likely for the As-rich composition. It can be also perceived that the contributions coming from the minority components, i.e. As-As for $\mathrm{Cd}_{59} \mathrm{As}_{41}$ and $\mathrm{Cd}-\mathrm{Cd}$ for $\mathrm{Cd}_{59} \mathrm{As}_{41}$, are very weak. Beyond the first peak region of the As-As PRDF for $\mathrm{Cd}_{59} \mathrm{As}_{41}$ these minority PRDFs are very close to the average density functions.

First, the near neighbour peak of the PRDFs was analysed. In order to fit the $\mathrm{Cd}$-As experimental PRDF for $\mathrm{Cd}_{59} \mathrm{As}_{41}$ a one-shell model was assumed. The coordination number $N_{\mathrm{Cd}-\mathrm{Cd}}$, the near neighbour interatomic distance $r_{\mathrm{Cd}-\mathrm{As}}$ and its standard deviation $\sigma_{\mathrm{Cd}-\mathrm{As}}$ were allowed to vary. The fitting procedure converged to the structural parameters $r_{\mathrm{Cd}-\mathrm{As}}=2.68 \AA, \sigma_{\mathrm{Cd}-\mathrm{As}}=0.09 \AA$ and $N_{\mathrm{Cd}-\mathrm{As}}=2.15$. The near neighbour region of the Cd-Cd PRDF can be satisfactorily fitted with

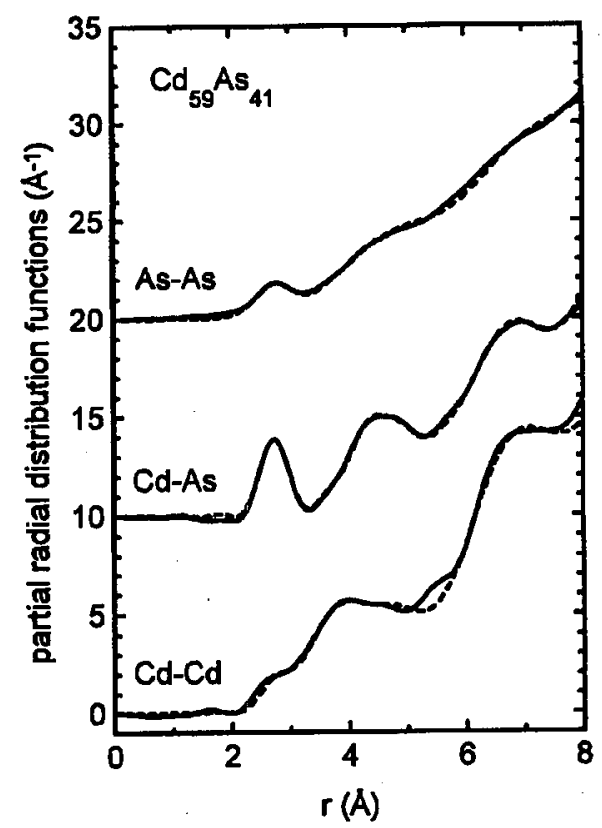

Fig. 1. The experimental (solid line) and model (dashed line) PRDFs for $\mathrm{Cd}_{59} \mathrm{As}_{41}$. 


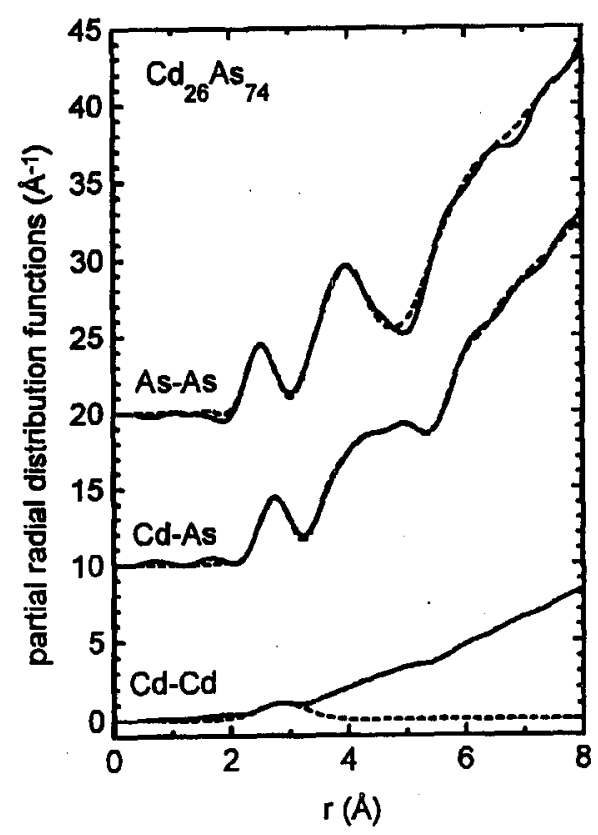

Fig. 2. The experimental (solid line) and model (dashed line) PRDFs for $\mathrm{Cd}_{26} \mathrm{As}_{74}$.

two shells. The resulting parameters are: $r_{\mathrm{Cd}-\mathrm{Cd}}^{(1)}=2.67 \AA, \sigma_{\mathrm{Cd}-\mathrm{Cd}}^{(1)}=0.1 \AA$, $N_{\mathrm{Cd}-\mathrm{Cd}}^{(1)}=0.8, r_{\mathrm{Cd}-\mathrm{Cd}}^{(2)}=3.20, \sigma_{\mathrm{Cd}-\mathrm{Cd}}^{(2)}=0.25 \AA$ and $N_{\mathrm{Cd}-\mathrm{Cd}}^{(2)}=1.2$. The first attempt to fit the As-As PRDF was made with the one-shell model. This fit led to the values: $r_{\mathrm{As}-\mathrm{As}}=2.72 \AA, \sigma_{\mathrm{As}-\mathrm{As}}=0.31 \AA$ and $N_{\mathrm{As}-\mathrm{As}}=1.64$. However, the two-shell model with $r_{\mathrm{As}-\mathrm{As}}^{(1)}=2.44 \AA, \sigma_{\mathrm{As}-\mathrm{As}}^{(1)}=0.22 \AA, N_{\mathrm{As}-\mathrm{As}}^{(1)}=0.4$, $r_{\mathrm{As}-\mathrm{As}}^{(2)}=2.76 \AA, \sigma_{\mathrm{As}-\mathrm{As}}^{(2)}=0.16 \AA$ and $N_{\mathrm{As}-\mathrm{As}}^{(2)}=0.7$ matches better the first peak of the As-As PRDF. The two-shell model of the Cd-Cd and As-As first coordination spheres suggests a certain degree of chemical disorder. Assuming tetrahedral coordination of both atoms and complete chemical disorder (the coordination numbers depending on the chemical composition) the near neighbour coordination numbers can be calculated $[8,9]$ being $N_{\mathrm{Cd}-\mathrm{Cd}}=2.36, N_{\mathrm{Cd}-\mathrm{As}}=1.64$ and $N_{\text {As-As }}=1.64$. The $N_{\text {Cd-Cd }}$ and $N_{\text {As-As }}$ values, resulting from the chemically disordered model are greater than the experimental coordination numbers, whereas $N_{\text {As-As }}$ is smaller. Taking into account the previous findings for Cd-rich compositions [6] one can calculate the coordination numbers for $\mathrm{Cd}_{59} \mathrm{As}_{41}$ starting from the model, based on the structure with the 1:1 stoichiometry, in which each $\mathrm{Cd}$ is coordinated by $1 \mathrm{Cd}$ and $3 \mathrm{As}$ and each $\mathrm{As}$ by $1 \mathrm{As}$ and $3 \mathrm{Cd}$. Assuming that the As-positions are statistically occupied by $\mathrm{As}$ and $\mathrm{Cd}$, in the proportions depending on the chemical concentration, the estimated coordination numbers are: $N_{\mathrm{Cd}-\mathrm{Cd}}=1.54, N_{\mathrm{Cd}-\mathrm{As}}=2.46$ and $N_{\mathrm{As}-\mathrm{As}}=0.46$. A comparison of the experimental coordination numbers and those estimated from the models also suggests a certain degree of chemical disorder. 
Similar fitting procedures were performed for $\mathrm{Cd}_{26} \mathrm{As}_{74}$. The obtained structural parameters are: $r_{\mathrm{Cd}-\mathrm{Cd}}=2.8 \AA, \sigma_{\mathrm{Cd}-\mathrm{Cd}}=0.37 \AA, N_{\mathrm{Cd}-\mathrm{Cd}}=1.1$, $r_{\mathrm{Cd}-\mathrm{As}}=2.7 \AA, \sigma_{\mathrm{Cd}-\mathrm{As}}=0.15 \AA, N_{\mathrm{Cd}-\mathrm{As}}=2.7, r_{\mathrm{As}-\mathrm{As}}=2.47 \AA, \sigma_{\mathrm{As}-\mathrm{As}}=$ $0.056 \AA$ and $N_{\mathrm{As}-\mathrm{As}}=2.4$. However, the Cd-Cd coordination number is uncertain because the first peak in the Cd-Cd PRDF is practically merged in the average density function. This indicates that the $\mathrm{Cd}$ atoms are almost randomly distributed in the network formed by the As atoms. The coordination numbers calculated for the chemically disordered model are: $N_{\mathrm{Cd}-\mathrm{Cd}}=1.04, N_{\mathrm{Cd}-\mathrm{As}}=2.96$ and $N_{\mathrm{As}-\mathrm{As}}=2.96$. The comparison with the experimental values leads to the conclusion that $\mathrm{Cd}_{26} \mathrm{As}_{74}$ is chemically disordered.

Beyond the first peak regions the PRDFs were calculated for the models, which are based on the structures of the crystalline polymorphs of the Cd-As system $\mathrm{CdAs}$ and $\mathrm{CdAs}_{2}$. The basic structures are described in detail in [5, 6]. As it can be seen from Figs. 1 and 2, the experimental and calculated PRDFs are in good agreement supporting the proposed structural models.

\section{Summary}

The obtained results demonstrate the ability of the AWAXS technique to provide structural information which cannot be obtained using other methods. From an analysis of the PRDFs it was found that the $\mathrm{Cd}$ and As atoms are tetrahedrally coordinated in both investigated films and their arrangements are to a certain degree chemically disordered.

\section{References}

[1] D.T. Keating, J. Appl. Phys. 34, 923 (1963).

[2] Y. Waseda, Novel Application of Anomalous X-ray Scattering for Structural Characterization of Disordered Materials, Lecture Notes in Physics, Vol. 204, Springer-Verlag, Berlin 1984.

[3] A. Burian, in: Zastosowanie Promieniowania Synchrotronowego, Ed. E. Sobczak, Wyd. im. W. Świętoslawskiego, Warszawa 1996, p. 51.

[4] A. Burian, to be published.

[5] A. Burian, P. Lecante, A. Mosset, J. Galy, J.M. Tonnerre, D. Raoux, J. Non-Cryst. Solids 164-166, 151 (1993).

[6] A. Burian, P. Lecante, A. Mosset, J. Galy, J.M. Tonnerre, D. Raoux, submitted to J. Non-Cryst. Solids.

[7] H.P. Kunzi, H.G. Tzschach, C.A. Zehnder, Numerical Methods of Mathematical Optimization with FORTRAN Programs, Academic Press, New York 1971.

[8] G.S. Cargill, F. Spaepen, J. Non-Cryst. Solids 43, 91 (1981).

[9] S.J. Gurman, J. Non-Cryst. Solids 139, 107 (1992). 